ORIGINAL ARTICLE

\title{
Sexually transmitted infections in male clients of female sex workers in Benin: risk factors and reassessment of the leucocyte esterase dipstick for screening of urethral infections
}

\author{
M Alary, C M Lowndes, L Mukenge-Tshibaka, C A B Gnintoungbé, E Bédard, N Geraldo, P Jossou, \\ E Lafia, F Bernier, É Baganizi, J R Joly, E Frost, S Anagonou
}

Sex Transm Infect 2003;79:388-392

See end of article for authors' affiliations

Correspondence to: Michel Alary, MD, Unité de recherche en santé des populations, Centre hospitalier affilié universitaire de Québec, 1050, chemin Sainte-Foy, Québec, G1S 4L8, Canada; michel.alary@ uresp.ulaval.ca

Accepted for publication 24 March 2003
Chlamydia trachomatis, Neisseria Objectives: (1) To assess risk factors for urethral infections with Chlamydia trachomatis, Neisseria
gonorrhoeae, and Trichomonas vaginalis among male clients of female sex workers (FSWs) in Benin; (2) to study the validity of LED testing of male urine samples compared to a highly sensitive gold standard (PCR) for the diagnosis of urethral infections with the organisms cited above.

Methods: Male clients of FSWs $(n=404)$ were recruited on site at prostitution venues in Cotonou, Benin, between 28 May and 18 August 1998. A urine sample was obtained from each participant just before he visited the FSW, and tested immediately using a leucocyte esterase dipstick (LED) test. It was then tested for HIV using the Calypte EIA with western blot confirmation, and for $C$ trachomatis, $N$ gonorrhoeae, and $T$ vaginalis by PCR. After leaving the FSW's room, participants were interviewed about demographics, sexual behaviour, STI history and current symptoms and signs, and were examined for urethral discharge, genital ulcers, and inguinal lymphadenopathies.

Results: STI prevalences were: C trachomatis, 2.7\%; $N$ gonorrhoeae, 5.4\%; either chlamydia or gonorrhoea 7.7\%; T vaginalis 2.7\%; HIV, 8.4\%. Lack of condom use with FSWs and a history of STI were independently associated with $C$ trachomatis and/or $N$ gonorrhoeae infection. Over $80 \%$ of these infections were in asymptomatic subjects. The overall sensitivity, specificity, positive and negative predictive values of the LED test for detection of either C trachomatis or N gonorrhoeae were $48.4 \%$, $94.9 \%, 44.1 \%$, and $95.7 \%$, respectively. In symptomatic participants $(n=22)$, all these parameters were $100 \%$ while they were $47.4 \%, 94.7 \%, 37.5 \%$, and $96.4 \%$ in asymptomatic men $(n=304)$.

Conclusions: Since most STIs are asymptomatic in this population, case finding programmes for gonorrhoea and chlamydia could be useful. The performance characteristics of the LED test in this study suggest that it could be useful to detect asymptomatic infection by either $C$ trachomatis or $N$ gonorrhoeae in high risk men.
1 $\mathrm{n}$ developing countries, preventive interventions for HIV and sexually transmitted infections (STIs) directed at high risk populations often target female sex workers (FSWs), even though the male clients of these women also represent a significant source of STIs and HIV, as well as acting as a bridge for disease transmission between FSWs and women in the general population. In fact, reports from sub-Saharan Africa have shown high prevalence of HIV in clients of FSWs ${ }^{1}$ and in populations of men frequently using prostitution services, ranging from $8.4 \%$ to $56 \%{ }^{2-4}$ Despite these dramatic figures, these men are rarely specific targets for intervention because they are considered very hard to reach. ${ }^{5-8}$

A better understanding of sociodemographic and behavioural characteristics associated with STIs and HIV in male clients of FSWs in Africa could aid in the formulation of effective interventions for their prevention. STI control and HIV prevention strategies in men should also focus on the diagnosis and treatment of curable STIs. Such a combined strategy, including promotion of condom use as well as detection and treatment of STIs, has been shown to reduce the prevalence of these diseases and of HIV infection among FSWs in sub-Saharan Africa. ${ }^{9-12}$

In the developing world, diagnosis and treatment of STIs are generally based on the syndromic approach, a strategy that has been shown to be effective for male urethritis. ${ }^{13}{ }^{14}$
However, results from several studies suggest that a significant proportion of men with positive laboratory tests for Chlamydia trachomatis or Neisseria gonorrhoeae in their urethra are asymptomatic. ${ }^{15-18}$ Trichomonas vaginalis has also been shown to be an important cause of urethral infection in some African settings, including in asymptomatic men. ${ }^{16}{ }^{17}$ The leucocyte esterase dipstick (LED) test has been proposed as a cheap non-specific test that could allow the detection of polymorphonuclear cells in asymptomatic men and also be used to confirm symptomatic urethritis. ${ }^{19-21}$ However, most studies evaluating the LED test were performed in the era preceding the wider use of nucleic acid amplification tests (NAAT) and showed sensitivities varying from 50\% to $100 \%$ and specificities between $50 \%$ and $80 \% .{ }^{15-23}$ With such results, in most instances, LED was not recommended as a screening test because of its low positive predictive value, nor was it considered particularly useful in symptomatic patients. More recently, Bowden carried out a study in Australia on the validity of the LED compared to NAAT (in this case, polymerase chain reaction, PCR) for the detection of $C$ trachomatis or $N$ gonorrhoeae in urine among a population of largely asymptomatic men. ${ }^{24}$ He used a cut-off value of trace for the LED test to maximise the negative predictive value with the objective of selecting men for whom it would be useful to perform the PCR assay. The use of this cut off 
yielded a sensitivity and specificity of $77.8 \%$ and $80.8 \%$, respectively. From the detailed results of the study, it can be observed that a $1+$ cut off for the LED test would result in a sensitivity of $50 \%$ and a specificity of $93.6 \%$, this latter figure being higher than any previously reported.

The objectives of this study were: (1) to evaluate risk factors for urethral infections by $C$ trachomatis, $N$ gonorrhoeae, and $T$ vaginalis among male clients of FSWs in Benin; $(2)$ to study the validity of LED testing of male urine samples compared to a highly sensitive gold standard (PCR) for the diagnosis of urethral infections caused by the agents cited above.

\section{METHODS \\ Background}

This study was undertaken within a larger project whose overall aim was to document the STI/HIV epidemiological situation among clients of FSWs in Cotonou, Benin, the sociodemographic characteristics of these men and their sexual behaviour with FSWs and other female partners. ${ }^{1}$ Health seeking behaviour for STIs was also investigated, as was the feasibility of interventions targeting these men. The study was conducted in Cotonou, the largest city of Benin with approximately 800000 inhabitants. In this city, an ongoing (started in 1993) HIV/STI intervention project funded by the Canadian International Development Agency targets FSWs for HIV and STI prevention. The project strategies involve promotion of correct condom use and free STI treatment according to local syndromic approach guidelines, including a screening algorithm for FSWs. ${ }^{25}$

\section{Study population and study procedures}

The data collection period for this study was between 28 May and 18 August 1998. The study population consisted of male clients of FSWs recruited directly at 13 different prostitution sites (not selected randomly, but chosen to ensure a diversity of types of prostitution venues and adequate geographical distribution in the city) between $8 \mathrm{pm}$ and $1 \mathrm{am}$. The study was proposed to the men by a field worker in collaboration with the FSWs themselves and the bar and brothel owners. The study was entirely anonymous and there was no payment made for participation. However, free condoms were given to participants and, in case of STI symptoms or signs or when the LED test was positive (see below for procedures), STI treatment was provided at no charge. The study procedures were performed on site in a room or a curtained off space outside provided by the bar or brothel owner. After verbal informed consent, a first void urine sample was obtained from each participant just before he went into a room with the FSW to have sex. After the client came out of the FSW'S room, he was interviewed for a duration of 15-30 minutes on demographics, sexual behaviour, STI history, and current symptoms as well as on health seeking behaviour for STIs. Thereafter, the genital area was examined for the presence of urethral discharge, ulcers, and inguinal lymphadenopathies. Ethical approval for this study was given by the ethics committee of the Centre hospitalier affilié universitaire de Québec and by the Ministry of Health, Benin.

\section{Laboratory procedures}

A LED (Chemstrip 10A, Boehringer Mannheim, Québec, Canada) test was performed on the urine sample immediately after collection on site and aliquots were stored at $4^{\circ} \mathrm{C}$ for HIV testing and at $-20^{\circ} \mathrm{C}$ for PCR testing for STIs. HIV testing was performed locally in Cotonou and in Montreal, Canada, with the Calypte EIA (Calypte Biomedical Corporation, Berkeley, CA, USA) followed by western blot confirmation (Cambridge Biotech/Calypte Biomedical
Corporation). ${ }^{26}$ The Amplicor CT/NG detection kit from Roche Diagnostics was performed in Montreal for detection of chlamydial and gonococcal infections. Finally, an in-house PCR for Trichomonas vaginalis targeting the 650 base pair repetitive sequence was performed in the Department of Microbiology of the Université de Sherbrooke, using an adaptation ${ }^{27}$ of the procedure of Shaio and collaborators. ${ }^{28}$

\section{Data analysis}

The data were analysed using Epi-Info (Center for Diseases Control and Prevention, USA, World Health Organization, Geneva, Switzerland) and SAS (SAS Institute, Cary, NC, USA). For the analysis of STI risk factors, the prevalence odds ratio (POR) was used as the measure of association. The $\chi^{2}$ and Fisher's exact tests were used for univariate analysis whereas logistic regression was used for multivariate analysis. We calculated the sensitivity and specificity (with $95 \%$ confidence intervals) as well as the positive and negative predictive values of the LED test, using a cut off of $1+$, meaning that samples with a result greater than trace were considered LED positive (the possible values for the test were: negative, trace, $1+$, and $2+$ ), in comparison with a gold standard based on PCR results.

\section{RESULTS}

A total of 404 male clients of FSWs provided a urine sample over 47 nights of data collection between 28 May and 18 August, 1998. From 17 June to 18 August, the numbers of clients refusing to participate in the study were recorded. Of 486 clients approached, $329(67.7 \%)$ accepted and 157 $(32.3 \%)$ declined participation. Of the 404 subjects who provided a urine sample, $330(81.7 \%)$ answered the questionnaire and 298 (73.8\%) had a physical examination. Among those answering the questionnaire, median age was 25.5 years (range 17-53). Overall, 34 (8.4\%) of the participants were infected with HIV; 22 (5.4\%) with $N$ gonorrhoeae; $11(2.7 \%)$ with $C$ trachomatis; 11 (2.7\%) with $T$ vaginalis; 31 (7.7\%) with either $N$ gonorrhoeae or $C$ trachomatis; and $41(10.1 \%)$ with any of the latter three pathogens.

Among the 326 men who provided information on STI symptoms, seven $(2.1 \%)$ reported urethral discharge while 17 $(5.2 \%)$ complained of dysuria. Physical examination revealed that six clients out of $298(2.0 \%)$ had genital ulcers while presence of urethral discharge was confirmed in three men (1.0\%). Overall, 22 men reported either dysuria or urethral discharge or had discharge upon clinical examination. Table 1 shows the association between symptoms/signs of urethritis and STIs.

Table 1 also shows the risk factors other than symptoms/ signs associated with the different STIs studied. Factors that did not show any significant association with STIs include age, ethnicity, country of origin, city of residence, marital status, and frequency of visits to FSWs. Whereas price paid to FSW, STI history, and current urethritis signs/symptoms were significantly associated with infection by either $N$ gonorrhoeae or $C$ trachomatis (all p <0.05), none of these variables were significantly related to $T$ vaginalis infection. Even though current urethritis signs/symptoms were associated with gonococcal or chlamydial infection, the majority of the men infected with either pathogen $(81.3 \%)$ were asymptomatic.

For the multivariate analysis (table 2), we entered all the variables identified as risk factors in the univariate analysis in a multiple logistic regression model (for condom use, since there was a strong correlation between the two condom use variables shown in table 1 , we chose to enter in the model only the variable on condom use with FSWs in general). In this analysis, history of previous STI and condom use were significantly associated with chlamydial or gonococcal 
Table 1 Univariate analysis of clinical signs/symptoms and risk factors for $\mathrm{N}$ gonorrhoeae, $C$ trachomatis, and $T$ vaginalis infection among male clients of FSWs in Cotonou, Benin

\begin{tabular}{|c|c|c|c|c|c|c|c|}
\hline $\begin{array}{l}\text { Symptoms/signs } \\
\text { or risk factor }\end{array}$ & No & $\begin{array}{l}\text { No }(\%) \text { with } \\
\text { NG* }^{*} \text { or } \mathrm{CT} \dagger\end{array}$ & $\begin{array}{l}\text { Prevalence } \\
\text { odds ratio }\end{array}$ & p Valueł & $\begin{array}{l}\text { No (\%) with } \\
\text { TV§ }\end{array}$ & $\begin{array}{l}\text { Prevalence } \\
\text { odds ratio }\end{array}$ & p Value \\
\hline \multicolumn{8}{|c|}{ Current symptoms and/or signs ${ }^{\emptyset}$} \\
\hline Yes & 22 & $5(22.7)$ & \multirow[t]{2}{*}{4.4} & \multirow[t]{2}{*}{0.02} & $2(9.1)$ & \multirow[t]{2}{*}{4.2} & \multirow[t]{2}{*}{0.12} \\
\hline No & 304 & $19(6.3)$ & & & $7(2.3)$ & & \\
\hline \multicolumn{8}{|c|}{ Price paid to FSW } \\
\hline$\leqslant 1$ US $\$$ & 202 & $20(9.9)$ & \multirow[t]{2}{*}{3.3} & \multirow[t]{2}{*}{0.03} & $6(3.3)$ & \multirow[t]{2}{*}{1.3} & \multirow[t]{2}{*}{0.76} \\
\hline$>$ IUS $\$$ & 124 & $4(3.2)$ & & & $3(2.4)$ & & \\
\hline \multicolumn{8}{|c|}{ Condom use with FSW just seen } \\
\hline No & $144^{\circ}$ & $17(11.8)$ & \multirow[t]{2}{*}{3.4} & \multirow[t]{2}{*}{$<0.01$} & $5(3.5)$ & \multirow[t]{2}{*}{1.6} & \multirow[t]{2}{*}{0.49} \\
\hline Yes & 182 & $7(3.9)$ & & & $4(2.2)$ & & \\
\hline \multicolumn{8}{|c|}{ Condom use with FSW in general } \\
\hline Always/mostly & 173 & $7(4.1)$ & 1.0 & \multirow{4}{*}{$<0.01^{* *}$} & $8(4.7)$ & 1.0 & \multirow{4}{*}{$0.11^{\star *}$} \\
\hline Sometimes & 67 & $4(6.0)$ & 1.5 & & $0(0.0)$ & 0.0 & \\
\hline Never & 83 & $13(15.7)$ & 4.4 & & $1(1.2)$ & 0.3 & \\
\hline \multicolumn{6}{|l|}{ STI history } & & \\
\hline Yes & 161 & $20(12.4)$ & \multirow[t]{2}{*}{5.8} & \multirow[t]{2}{*}{$<0.01$} & $6(3.7)$ & \multirow[t]{2}{*}{2.1} & \multirow[t]{2}{*}{0.29} \\
\hline $\begin{array}{l}\text { No } \\
\text { Education }\end{array}$ & 166 & $4(2.4)$ & & & $3(1.8)$ & & \\
\hline Primary/none & 137 & $15(11.0)$ & \multirow[t]{2}{*}{2.5} & \multirow[t]{2}{*}{0.03} & $2(1.5)$ & \multirow[t]{2}{*}{0.4} & \multirow[t]{2}{*}{0.8} \\
\hline$\geqslant$ high school & 193 & $9(4.7 \%)$ & & & $7(3.6 \%)$ & & \\
\hline
\end{tabular}

infection, whereas urethritis signs/symptoms were only of borderline significance.

The LED test was positive in 34 of the 404 subjects (8.4\%). The overall sensitivity, specificity, positive and negative predictive values of the LED test, in comparison with the gold standard PCR results, for the detection of either $C$ trachomatis or $N$ gonorrhoeae, are shown in table 3 . Whereas among symptomatic men the concordance between LED and PCR results was perfect, among asymptomatic men the sensitivity was just under $50 \%$ and the specificity approximately $95 \%$, resulting in a positive predictive value of $37.5 \%$. In contrast with the very strong association between LED positivity and an infection with either $N$ gonorrhoeae or $C$ trachomatis $(\mathrm{p}<0.0001)$, there was no significant association between a positive LED test and the presence of $T$ vaginalis $(\mathrm{p}=0.24)$, irrespective of symptoms. The performance of the LED test to detect $T$ vaginalis was thus very poor, with a sensitivity of $18.2 \%$ (95\% CI: 2.8 to 51.8 ), a specificity of 91.9\% (95\% CI: 88.7 to 94.4 ), a positive predictive value of $5.9 \%$, and a negative predictive value of $97.6 \%$.

\section{DISCUSSION}

Our data show that about $8 \%$ of male clients of FSWs in Cotonou were infected with either $N$ gonorrhoeae or $C$ trachomatis. Similar results were found by Steen and colleagues, who reported a prevalence of $10.9 \%$ for $N$ gonorrhoeae or $C$ trachomatis among male clients of FSWs in South Africa. ${ }^{29}$ The prevalence of $T$ vaginalis infection was relatively low in our study population and was not associated

Table 2 Multivariate analysis of risk factors for infection by either $\mathrm{N}$ gonorrhoeae or $\mathrm{C}$ trachomatis among male clients of FSWs in Cotonou, Benin

\begin{tabular}{llll}
\hline Factor & POR $^{*}$ & $\mathbf{9 5 \%} \mathbf{C l}$ & $\mathbf{p ~ V a l u e ~}$ \\
\hline Condom use with FSW in general & & & \\
Always/mostly & 1.0 & & \\
Sometimes & 1.1 & $0.3-3.9$ & $<0.01 \dagger$ \\
Never & 4.2 & $1.5-11.3$ & \\
STI history & 6.0 & $1.9-18.5$ & $<0.01$ \\
Current urethritis symptoms/signs & 3.0 & $0.9-9.8$ & 0.06 \\
\hline
\end{tabular}

*Prevalence odds ratio; ttest for trend. with known STI risk factors in our data. In studies carried out in Kenya ${ }^{17}$ and Tanzania, ${ }^{16} T$ vaginalis was much more frequent than either $N$ gonorrhoeae or $C$ trachomatis in truck drivers and men in the general population, respectively, independently of the presence of symptoms. In a study on aetiology of urethritis in five west African countries, the prevalence of $T$ vaginalis varied considerably from one country to the other, from $2.5 \%$ in Côte d'Ivoire to $24.5 \%$ in Senegal. ${ }^{30}$ In the latter study, the prevalence of $T$ vaginalis among men consulting for urethral discharge in Benin was $8.1 \%$. These results are compatible with ours for the subgroup of symptomatic men (prevalence of $9.1 \%$, table 1 ), and suggest important geographical variations in the prevalence of $T$ vaginalis.

Among symptomatic subjects, the prevalence of gonorrhoea or chlamydial infection was low at only $22.7 \%$. One reason for this could be that we did not screen the participants for Mycoplasma genitalium. This organism was found to be the most common cause of non-gonococcal urethritis in a study by Morency and colleagues in Bangui, Central African Republic, ${ }^{27}$ and one important aetiological agent of urethral discharge in west Africa. ${ }^{30}$ Furthermore, studies on symptomatic men such as those mentioned above $^{27}{ }^{30}$ generally enrol subjects consulting spontaneously at health centres for their symptoms. In our study, enrolment

Table 3 Performance of the LED test in the diagnosis of $C$ trachomatis and/or $N$ gonorrhoeae among male clients of FSWs in Cotonou, Benin

\begin{tabular}{|c|c|c|c|}
\hline & $\begin{array}{l}\text { All men } \\
(n=404)\end{array}$ & $\begin{array}{l}\text { Symptomatic } \\
\text { men }^{*}(n=22)\end{array}$ & $\begin{array}{l}\text { Asymptomatic } \\
\text { men }(n=304)\end{array}$ \\
\hline $\begin{array}{l}\text { No }(\%) \text { with NG } \\
\text { or } \mathrm{CT}\end{array}$ & $31(7.7 \%)$ & $5(22.7 \%)$ & 19 (6.3\%) \\
\hline $\begin{array}{l}\text { Sensitivity (\%) } \\
(95 \% \mathrm{Cl})\end{array}$ & $\begin{array}{l}48.4 \\
\text { (31.3 to } 65.7)\end{array}$ & $\begin{array}{l}100 \\
(47.3 \text { to } 100)\end{array}$ & $\begin{array}{l}47.4 \\
(26.1 \text { to } 69.4)\end{array}$ \\
\hline Specificity (\%) & 94.9 & 100 & 94.7 \\
\hline$(95 \% \mathrm{Cl})$ & (92.3 to 96.8 ) & (84.7 to 100 ) & (91.7 to 96.9$)$ \\
\hline PPV (\%) & 44.1 & 100 & 37.5 \\
\hline NPV (\%) & 95.7 & 100 & 96.4 \\
\hline
\end{tabular}

*Men with urethritis signs/symptoms.

$\mathrm{NG}=$ Neisseria gonorrhoeae; $\mathrm{CT}=$ Chlamydia trachomatis $\mathrm{PPV}=$ positive predictive value; $\mathrm{NPV}=$ negative predictive value. 
was not based on spontaneous complaints, but symptoms were rather actively elicited from all participants. This could well lead to an overestimation of the frequency of symptoms and, consequently, to a lower STI prevalence than that observed in studies on men with spontaneous complaints of dysuria or urethral discharge. This is very likely given that urethral discharge was confirmed in only three men on clinical examination. Finally, PCR on urine samples is less sensitive than on urethral swabs, ${ }^{31}$ although it is still considered an acceptable screening test, ${ }^{31}$ whereas the use of PCR on female urine samples can be much more problematic with reported sensitivities as low as $54 \%$. $^{32}$

In Cotonou, a study carried out among FSWs, at the same time as this one, demonstrated high prevalence of $N$ gonorrhoeae or $C$ trachomatis among these women $(24.5 \%) .{ }^{10}$ Similar results were reported from the study by Steen et al (24.9\% among FSWs). ${ }^{29}$ The observed difference in STI prevalence among FSWs and their male clients may be attributed to the fact that duration of infection is generally longer in women than in men (women being more often asymptomatic than men) and that women are more susceptible than men to acquiring these infections, as well as much more frequently exposed to STIs. In fact, while the median number of visits to FSWs by the clients was 24 per year in this study, ${ }^{1}$ the corresponding figure for FSWs was 17 male clients per week. ${ }^{10}$

In multivariate analysis, gonorrhoea or chlamydial infection was associated with lack of condom use with FSW and STI history. Lower price paid to the FSW, as well as lower educational level, which were also associated with these infections in univariate analysis, did not remain significantly associated in the final multivariate model, probably because they were found to be predictors of condom use in this population. ${ }^{1}$ Although condom use rates by clients with the FSW just seen were suboptimal at $56 \%,{ }^{1}$ our data nevertheless provide further evidence for the protective effect of condom use on STIs. The association with a history of STI, however, underlines the need for intensive preventive counselling of men when an STI is diagnosed. The recurrence of STIs in these men indicates that this opportunity is being lost in current clinical practice in Benin.

The fact that the vast majority $(>80 \%)$ of infections with $N$ gonorrhoeae or $C$ trachomatis were asymptomatic in this population suggests that case finding programmes in this high risk male population could be very useful. Such programmes could include regular sessions of LED testing at prostitution venues, inspired from the methodology used in this study, as well as the development and promotion of specific clinical services for high risk men where LED testing would be available.

\section{Key points}

- About $10 \%$ of the clients of female sex workers in Cotonou, Benin, had a urethral infection caused by Neisseria gonorrhoeae, Chlamydia trachomatis, or Trichomonas vaginalis.

- Lack of condom use and previous history of STI were associated with infection by $N$ gonorrhoeae or $C$ trachomatis, whereas no specific factor was associated with $T$ vaginalis.

- The leucocyte esterase dipstick (LED) test performed relatively well for the detection of $N$ gonorrhoeae and $C$ trachomatis, but not for the detection of $T$ vaginalis.

- STI case finding among high risk men in developing countries is a priority and the LED test could be useful for this purpose.
In our study, the performance of the LED test was very similar to that derived from the data presented by Bowden, ${ }^{24}$ with a sensitivity of around $50 \%$ and a specificity of around 95\%. In another recent study, comparing LED to ligase chain reaction (LCR) for chlamydial infection only, the results were even better, with a sensitivity of $87.5 \%$ and a specificity of $92.4 \% .^{33}$ These results suggest that the LED test has a much better specificity (and thus higher positive predictive value) than when previously evaluated in comparison with nonNAAT technologies. ${ }^{15}{ }^{17-23}$ Although schistosomiasis has been associated with a positive LED test ${ }^{1622}$ and could have resulted in a poor specificity in studies carried out in east Africa where the prevalence of this parasitic infection is relatively high, it could not have affected results of studies conducted in developed countries ${ }^{18-21}$ where poor specificity of the LED test has also been reported. It thus appears that some true cases were detected by the LED test but not by non-NAAT technologies, resulting in an apparent lack of specificity of the former.

Such results suggest that LED could be a useful case finding tool in high risk men in developing countries. Indeed, in our study, the positive predictive value of the LED test among asymptomatic men was $37.5 \%$, a figure which, although lower than is generally found for the syndromic approach in the management of men presenting with symptoms of urethral discharge, is much higher than that of another standard of care for STI management in developing countries, the syndromic approach for the diagnosis of cervical infections among symptomatic women. ${ }^{34}$ In addition, the fact that the LED test is rapid and inexpensive and can be administered at the point of care makes it a particularly useful test in a context where high rates of non-attendance for return visits occur, as shown for example in FSWs in Cotonou. ${ }^{35}$ It has been shown that even in the industrialised world, non-attendance for follow up visits can have a negative impact on STI treatment rates. ${ }^{36}$

In our study, the LED test had perfect performance parameters in symptomatic men. However, these findings are based on a very small number of men and need to be confirmed by other studies.

In conclusion, the performance of the LED test in our study suggests that it could be a useful case finding tool for STIs in high risk asymptomatic men in developing countries. Given the fact that the prevalence of STIs in clients of FSWs was found to be much higher than that of the general population of men in Cotonou ( $1 \%$ for gonorrhoea and $2 \%$ for chlamydial infection ${ }^{37}$ ), and that these men constitute a bridge between FSWs and the general population of women in terms of STI and HIV transmission, ${ }^{38}$ interventions targeted towards this population, involving both STI screening and treatment and outreach prevention activities, are urgently needed.

\section{ACKNOWLEDGEMENTS}

The study was funded in part by the project "Appui à la lutte contre le sida en Afrique de l'ouest" executed by CCISD Inc and funded by CIDA Canada. HIV-1 urine EIA and western blot diagnostic kits were donated by Calypte Biomedical Corporation, USA. We appreciate the help from our field workers Marguerite Kpikpitse and Ibrahim Camara. We thank female sex workers for their collaboration and bar/brothel owners for accepting us on site and for assistance in recruitment. Finally, we acknowledge the contribution of Sylvie Deslandes for laboratory analyses.

\section{CONTRIBUTORS}

MA was a co-principal investigator, was responsible for the data analyses related to this article and was the main writer of the manuscript; CML was a co-principal investigator and contributed to data analysis and to the writing of the manuscript; LMT contributed to data analysis and to the writing of the manuscript; CABG was responsible for data collection in the field and contributed to data analyses; EB, NG, and PJ contributed to the data collection; EF was 
responsible for the laboratory tests carried out in Cotonou; FB and JRJ were responsible for the laboratory tests for chlamydial and gonococcal infections; EF was responsible for the PCR testing for trichomonas. EB and SA were the local co-investigators and contributed to the organisation and implementation of the study. All authors contributed to the interpretation of the data and reviewed and commented the manuscript.

\section{Authors' affiliations}

M Alary, C M Lowndes, L Mukenge-Tshibaka, E Bédard, Unité de recherche en santé des populations, Centre hospitalier affilié universitaire de Québec, Québec, Canada

C M Lowndes, HIV and STI Division, PHLS Communicable Disease Surveillance Centre, London, UK

C A B Gnintoungbé, É Baganizi, Projet SIDA 3-Bénin, Cotonou, Bénin N Geraldo, Dispensaire MST, Centre de Santé de Circonscription Urbaine Cotonou 1, Bénin

P Jossou, S Anagonou, Faculté des sciences de la santé, Université Nationale du Bénin

E Lafia, S Anagonou, Programme national de lutte contre le Sida et les MST (PNLS), Bénin

F Bernier, Héma Québec, Montréal, Canada

É Baganizi, Centers for Disease Control and Prevention, Atlanta, GA, USA

J R Joly, Laboratoire de santé publique du Québec, Sainte-Anne-deBellevue, Canada

E Frost, Département de Microbiologie, Université de Sherbrooke,

Québec, Canada

\section{REFERENCES}

1 Lowndes CM, Alary M, Gnintounbgè CAB, et al. Management of sexually transmitted diseases and HIV prevention in men at high risk: targeting clients and non-paying sexual partners of female sex workers in Benin. AIDS 2000;14:2523-34.

2 Ramiee G, Gouws aEE. Prevalence of HIV among truck drivers visiting sex workers in KwaZulu-Natal, South Africa. Sex Transm Dis 2002;29:44-9.

3 Lankaonde S, Meda N, Sangaore L, et al. HIV infection in truck drivers in Burkina Faso: a seroprevalence survey. Med Trop 1998;58:41-6.

4 Bwayo J, Plummer F, Omari $M$, et al. Human immunodeficiency virus infection in long-distance truck drivers in east Africa. Arch Intern Med 1994; 154:1391-6.

5 Mbugua GG, Muthami LN, Mutura CW, et al. Epidemiology of HIV infection among long distance truck drivers in Kenya. East Afr Med J 1995;72:515-8.

6 Faugier J, Cranfield S. Reaching male clients of female prostitutes: the challenge for HIV prevention. AIDS Care 1995;7(suppl 1):S21-32.

7 Day S, Ward H, Perrora L. Prostitution and risk of HIV: male partners of female prostitutes. BMJ 1993;307:359-61

8 Barnard MA, McKegarney NP, Leyland AH. Risk behaviours among male clients of female sex prostitutes. BMJ 1993;307:361-2.

9 Laga M, Alary M, Nzila N, et al. Condom promotion, sexually transmitted diseases treatment, and declining incidence of HIV- 1 infection in female Zairian sex workers. Lancet 1994;344:246-8.

10 Alary M, Mukenge-Tshibaka L, Bernier F, et al. Decline in the prevalence of HIV and sexually transmitted diseases among female sex workers in Cotonou, Benin, 1993-1999. AIDS 2002;16:463-70.

11 Meda N, Ndoye I, M'Boup S, et al. Low and stable HIV infection rates in Senegal: natural course of the epidemic or evidence for success of prevention? AIDS 1999;13:1397-405.

12 Ghys PD, Diallo MO, Ettiègne-Traoré $\mathrm{V}$, et al. Increase in condom use and decline in HIV and sexually transmitted diseases among FSW in Abidjan, Côte d'lvoire, 1991-1998. AIDS 2002;16:251-8.

13 Diajasumah T, Sudigdoadi S, Keersmaekers K, et al. Evaluation of syndromic patient management algorithm for urethral discharge. Sex Transm Infect 1998;74(Suppl 1):S29-33

14 Alary $M$, Baganizi $E$, Guèdèmè $A$, et al. Evaluation of clinical algorithms for the diagnosis of gonococcal and chlamydial infections among men with urethral discharge or dysuria and women with vaginal discharge in Benin. Sex Transm Infect 1998;74(Suppl 1):S44-9.

15 Grosskurth H, Mayaud P, Mosha F, et al. Asymptomatic gonorrhoea and chlamydial infection in rural Tanzanian men. BMJ 1996;312:277-80.

16 Watson-Jones D, Mugeye K, Mayaud P, et al. High prevalence of trichomoniasis in rural men in Mwanza, Tanzania: results from a population based study. Sex Transm Infect 2000;76:355-62.

17 Jackson DJ, Rakwar JP, Chohan B, et al. Urethral infection in a workplace population of East African men: evaluation of strategies for screening and management. J Infect Dis 1997:175:833-8.

18 Patrick DM, Rekart ML, Knowles L. Unsatisfactory performance of the leucocyte esterase test of first voided urine for rapid diagnosis of urethritis. Genitourin Med 1994;70:187-90.

19 Sellors JW, Mahony JB, Pickard L, et al. Screening urine with a leukocyłe esterase strip and subsequent chlamydial testing of asymptomatic men attending primary care practitioners. Sex Transm Dis 1993;20:152-6.

20 Shafer M, Schachter J, Moscicki AB, et al. Urinary leukocyte esterase screening test for asymptomatic chlamydial and gonococcal infections in males. JAMA 1989:262:2562-6.

21 O'Brien SF, Bell TA, Farrow JA. Use of leucocyte esterase dipstick to detect Chlamydia trachomatis and Neisseria gonorrhoeae urethritis in asymptomatic male detainees. Am J Public Health 1988;78:1583-4.

22 Mayaud P, Changalucha J, Grosskurth $\mathrm{H}$, et al. The value of urine specimens in screening for male urethritis and its microbial aetiologies in Tanzania. Genitourin Med 1992;68:361-5

23 Tyndall MW, Nasio J, Maitha G, et al. Leukocyte esterase urine strips for the screening of men with urethritis - use in developing countires. Genitourin Med 1994;70:3-6.

24 Bowden FJ. Reappraising the value of urine leukocyte esterase testing in the age of nucleic acid amplification. Sex Transm Dis 1998;25:322-6.

25 Germain $M$, Alary M, Guèdèmè $A$, et al. Evaluation of a screening algorithm for the diagnosis of genital infections with Neisseria gonorrhoeae and Chlamydia trachomatis among female sex workers in Benin. Sex Transm Dis 1997;24:109-15.

26 Berrios DC, Awins AL, Haynes-Sanstad K, et al. Screening for human immunodeficiency virus antibody in urine. Arch Pathol Lab Med 1995; 119:139-41.

27 Morency P, Dubois MJ, Gresenguet G, et al. Aetiology of urethral discharge in Bangui, Central African Republic. Sex Transm Infect 2001;77:125-9.

28 Shaio MF, Lin PR, Liu JY. Colorimetric one-tube nested PCR in detection of Trichomonas vaginalis in vaginal discharge. J Clin Microbiol 1997:32:132-8.

29 Steen R, Vuylsteke B, DeCotto T, et al. Evidence of declining STD prevalence in a South African mining community following a core group intervention. Sex Transm Dis 2000;27:1-8

30 Pepin J, Sobela F, Deslandes S, et al. Etiology of urethral discharge in West Africa: the role of Mycoplasma genitalium and Trichomonas vaginalis. Bull World Health Organ 2001;79:118-26.

31 Centers for Disease Control and Prevention. Screening tests to detect Chlamydia trachomatis and Neisseria gonorrhoeae infections -2002 MMWR 2002;51:RR-15.

32 Mukenge-Tshibaka L, Alary M, Bernier F, et al. Diagnostic performance of the Roche Amplicor PCR in detecting Neisseria gonorrhoeae in genitourinary specimens from female sex workers in Cotonou, Benin. J Clin Microbiol 2000;38:4076-9

33 Chernesky M, Jang D, Krepel J, et al. Impact of reference standard sensitivity on accuracy of rapid antigen detection assays and a leukocyte esterase dipstick for diagnosis of Chlamydia trachomatis from men. J Clin Microbiol 1999;37:2777-80

34 Van Dam CJ, Becker KM, Ndowa F, et al. Syndromic approach to STD case management: where do we go from here? Sex Transm Infect 1998;74(suppl 1):S175-8.

35 Mukenge-Tshibaka L, Alary $M$, Lowndes CM, et al. Syndromic versus laboratory-based diagnosis of cervical infections among female sex workers in Cotonou, Benin: implications of non-attendance for return visits. Sex Transm Dis 2002:29:324-30.

36 Gift TL, Pate MS, Hook III EW, Kassler WJ. The rapid test paradox: when fewer cases detected lead to more cases treated. Sex Transm Dis 1999;26:232-40.

37 Buvé A, Weiss HA, Laga $M$, et al. The epidemiology of gonorrhoea chlamydial infection and syphilis in four African cities. AIDS 2001;15(Suppl 4):S79-88.

38 Lowndes $\mathrm{CM}$, Alary M, Meda H, et al. Role of core and bridging groups in the transmission dynamics of HIV and STIs in Cotonou, Benin, West Africa. Sex Transm Infect 2002;78(Suppl 1):i69-i77. 